\title{
Organizational Support as Increment in Employee Resilience: A Comparative Study among Public and Private Employees
}

\author{
Haider ${ }^{1}$ and Abid $\mathbf{M}^{2 *}$ \\ 1Department of Applied Psychology, Bahauddin Zakariya University, Pakistan \\ ${ }^{2}$ Psychologist, Special Education Department Government of the Punjab, Pakistan \\ *Corresponding author: Momina Abid, Psychologist, Special Education Department, \\ Government of the Punjab, Pakistan, Tel: +923320797788; Email: \\ Mominaabid11@gmail.com
}

\section{Research Article}

Volume 1 Issue 1

Received Date: July 20, 2017

Published Date: August 04, 2017

DOI: $10.23880 /$ mhrij-16000103

\begin{abstract}
Despite the fact that getting attention in clinical psychology, so far only a few known about the employee resiliency in organizational contexts. This study aimed to investigate the correlational aspects of organizational support and employee resilience. It was also determined the organizational support as predictor of employee resilience. 129 employees were selected through purposive sampling from private and public sectors. Employees were asked to fill two scales perceived organizational support scale and employee resilience scale along with demographic sheet. Results showed positive correlation between the organizational support and employee resilience. Regression analysis revealed that organizational support has impact on employee resilience. Finding depicts the significant differences on organizational support among public and private employees but no differences were founded on employee resilience. Implication were discussed.
\end{abstract}

Keywords: Organizational Support; Employee Resilience; Public Employees; Private Employees

\section{Introduction}

Organizational support is essential as it sureties help gave by the association to manage the requesting conditions, and to do ones employment proficiently and adequately. Representatives should be esteemed and they are more concerned with the dedication of the association to them, and being esteemed by the association yield such advantages like pay, advancement, appreciation, different types of helps, and access to data by which they can convey their occupations better. Correspondence standard connected by both worker and manager in their relationship lead them with valuable results. At the point when individuals are dealt with well, the correspondence standard commits empowering satisfying once activity consequently.

Eisenberger (1990) [1] is one of the first driving pioneers of concentrating on perceived organizational support. In 1986 with the perception that representatives are keen on the association's Dedication however directors are occupied with benefitting from the association's dedication, perceived organizational support started. Specialists on POS expressed that in hierarchical exploration POS hypothesis is a standout amongst the most widely recognized measures of the remuneration 


\section{Mental Health \& Human Resilience International Journal}

standard. Organizational support makes more beneficial and more sensible society and in addition better environment. It likewise bolster identifies with representatives work fulfillment; prosperity; states of mind; full of feeling duty; positive mind-set; work execution; representatives moral inspiration; decency; and authoritative prizes. Eisenbergeretal (1986) [2] expressed that reward and motivating forces are valuable segments in keeping up workers' engagement, power, ingestion, commitment and loyalty. Perceived organizational support (POS) predicts and decides numerous predecessors, for example, work execution, work duty, work fulfillment, work devotion, and assignment execution.

Rhoades and Eisenberger (2002) expressed that perceived organizational support was straightforwardly connected with three classes of great treatment got by workers, for example, organizational prizes and good employment conditions, decency and manager backing, consequently ideal results are accomplished, for example, work fulfillment and hierarchical responsibility. Every one of these relations assists organizational support hypothesis. Mullen et al. (2006) analyzed that preparation impacts respondents results, duty, and exchange of preparing, because of preparing there is incredible change in the impression of perceived organizational support, and this change may be negative or positive and can be comprehend by watching pre and post preparing tests.

Organizational support ensure workers that the association is behind them when they confront an issue, execute their employment and handle unpleasant circumstances. As environment gets more focused representatives are more anxious about to what degree the organization pay attention on them and their success [2]. Expanding on meanings of employee resilience, representative strength is conceptualized in this as the limit of workers, encouraged and aided by the association, to use assets to absolutely adapt, adjust and flourish in light of changing work circumstances. This definition consolidates Luthans' (2002) portrayal of flexibility similar to a "developable limit" as opposed to a steady personality attribute as recommended in before hypotheses. Resilience in associations and among workers is significant in any connection which presents difficulties and change, and rises above a post-catastrophe setting. We in this way couple thorough exploratory techniques with specialist skill to urge associations to exploit representative strength, and aide the procedure of expanding organizational resilience and execution through staff capacities.
The employee resilience research group characterizes representative flexibility as a capacity to flourish in an evolving situation. This capacity is encouraged by the hierarchical connection, including initiative and authoritative society. This implies associations assume a key part in how well their representatives have the capacity to alter and perform under weight. An included advantage of representative strength concerns the positive overflow impacts flexible representatives will likewise be better prepared to handle challenges outside or work, and by encouraging worker flexibility, associations can bolster group versatility.

The versatility build has created in a few distinctive examination orders, and this has brought about a plenty of reasonable and operational definitions. Early versatility examination concentrated on individual level dispositional or quality like flexibility, characterizing it as "an identity trademark that conservatives the negative impacts of anxiety and advances adaption". This definition was produced in view of clinical investigations of kids who were "flourishing" in spite of their high hazard circumstances (being schizophrenic, having folks with dysfunctional behavior, living in neediness, managing abuse and brutality. These kids seemed, by all accounts, to be secured by an uncommon inward quality and characteristic versatile abilities. A percentage of the qualities normally connected with versatility were independence, self-regard, inward locus of control and self-viability (Wagnild \& Youthful, All things considered, our conceptualization goes past the meaning of strength proposed by Luthans, which recommends that it is a recuperation process in which one returns back to one's unique condition of harmony. Rather, our definition highlights the contemporary perspective of strength as a transformational process in which people adapt and effectively manage change as well as gain from it and adjust as needs be to flourish in the new environment [3]. The advancement of this limit implies that workers can use past encounters with change and affliction to be more adaptable and versatile later on [4-7], which thus encourages fruitful arrangement of difficulties. Our emphasis on flexibility as something that can be created, as opposed to a steady quality, additionally proposes that the organizational environment impacts the level of worker versatility through the procurement of empowering variables. We suggest that an open, strong, shared and learning focused workplace encourages representative flexibility. In view of this reason, the authoritative setting is urgent to the advancement of representative flexibility. 


\section{Mental Health \& Human Resilience International Journal}

\section{Rationale}

Nowadays Pakistan is moving towards a developing industrial state so it is necessary to focus on the behavior of organizations towards their employees. The purpose of this study is to investigate the effect of organizational support on employee resilience that how well the organization supports their employees in their wellbeing, growth, and how much the organization considers and value the goals of their employees. It is also the purpose of study to highlight the different qualities of the employees on work setting that how well they perform their tasks during work either they easily do the tasks or feel difficulties during work.

\section{Objectives}

- To assess the correlation of Perceived organizational support and Employee Resilience

- To assess the impact of Perceived organizational support on Employee Resilience

- To assess the differences of organizational support and employee resilience among public and private employees.

\section{Hypothesis}

- Perceived organizational support will be positively correlated with employee resilience

- Perceived organizational support will have impact on employee resilience

- Perceived organizational support and employee resilience will vary in terms of employee's job sector.

\section{Operational Definition}

Employee resilience: Employee resilience is conceptualized as an "employee capability, facilitated and supported by the organization, to utilize resources to continually adapt and flourish at work, even if/when faced with challenging circumstances".

Organizational Support: Organizational support is the assistance provided by the organization to deal with the demanding conditions, and to carry out ones job efficiently and effectively.

\section{Method}

\section{Participants}

129 employees were selected for the study which included 78 males and 51 females, which belong to different sectors and occupations. For this study purposive sampling technique was used that only those employees were included in the study, who were present during the time of data collection and who were willing to participate in the study.

\section{Instruments}

Two Instruments were used in the research.

1. Perceived Organizational Support scale

2. Employee Resilience scale

Perceived Organizational Support Scale: The survey of perceived organizational support [2] was used to assess levels of perceived organizational support. Factor analytic evidence from previous studies suggested that this survey forms a single factor and possesses adequate internal reliability [1,2]. The 12 items with the highest factor coefficients were employed in the present study. Among those 12 items, 3, 5, 6, 8, 10 and 12 are reverse scored. All scales utilized a 7 -point Likert-type format $(0=$ strongly disagree, 6 = strongly agree)

Employee Resilience Scale: Employee resilience scale is used to assess the level of resilience that how much a person is resilient at their work. 13 statements were included in this scale. Each item is scored and then added to obtain raw score. All scales utilized a 7-point Likerttype format ( 1 = strongly disagree, 7 = strongly agree $)$

\section{Procedure}

After briefing the booklet including two scales was administered to the respondent individually. The booklets given to employees and they were told they could ask any statement which seems difficult to understand. They were informed that they should try to answer the questions as honestly as possible. At the start of the form, the participants were asked to fill demographic sheet which contains age, gender, marital status, occupation, birth order, designation, year of work experience, and job place. Respondents were requested to mark just one option of every statement. Respondents were asked to read carefully each item of the scales one by one and give the answers, which they think would most appropriately describe their feelings. It was made clear that the information gathered would be kept strictly confidential and will be used only for research purpose. They were requested not to leave any question unanswered or to take any omission. After taking back these questionnaires, they were rechecked so that no item should remain unanswered. The scores were also calculated for all the 


\section{Mental Health \& Human Resilience International Journal}

dimensions collectively and scores of subscales were also calculated for individual dimensions.

\section{Results}

\begin{tabular}{|c|c|}
\hline & Employee Resilience \\
\hline Organizational Support & $174^{* *}$ \\
\hline
\end{tabular}

Table 1: Correlation Matrix's between Organizational Support and Employee Resilience

Note. $\mathrm{N}=129,{ }^{*} p<0.05$

Values depicted in table 1 show that there is significant positive correlation between perceived organizational support and employee resilience. If the level of perceived organizational support is high the level of employee resilience will also high.

\begin{tabular}{|c|c|c|c|c|c|}
\hline Predictor & $\mathrm{B}$ & Std. Error & $\mathrm{B}$ & $\mathrm{t}$ & $\mathrm{p}$ \\
\hline (Constant) & 63.15 & 5.591 & & 11.3 & $.000^{* * *}$ \\
\hline $\begin{array}{c}\text { Organizational } \\
\text { Support }\end{array}$ & 0.213 & 0.107 & 0.17 & 1.989 & $.049^{*}$ \\
\hline
\end{tabular}

Table 2: Regression Analysis showing Effect of organizational support on employee resilience

Note. $R^{2}=0.030$, Adjusted $R^{2}=0.023,(\mathrm{~F}(1,128)=3.956$, $* * * \mathrm{p}<0.001, * \mathrm{p}<0.05$

Table 2 indicated the significant positive effect of the organizational support on employee resilience.

\begin{tabular}{|c|c|c|c|c|c|}
\hline Job Sector & $\mathrm{N}$ & $\mathrm{M}$ & $\mathrm{SD}$ & $\mathrm{t}$ & $\mathrm{p}$ \\
\hline Private & 80 & 53.4 & 8 & & \\
\hline & & & & 3.25 & $.001^{*}$ \\
\hline Public & 49 & 48.9 & 7 & & \\
\hline
\end{tabular}

Table 3: Differences of Job Sector on the scale of perceived organizational support scale among Employees ( $\mathrm{N}=129)$

Note: $\mathrm{N}=129,{ }^{*} p<0.01$

Table 3 shows that significant differences in the level of organizational support among private and Public sector employees. As $p$ value is less than 0.05 it does prove about the significant differences. Private sector employees $(\mathrm{M}=53.35, \mathrm{SD}=7.81)$ have high level of organizational support as compare to public sector employees $(M=48.85$, $\mathrm{SD}=7.22$ ).

\begin{tabular}{|c|c|c|c|c|c|}
\hline Job Sector & $\mathrm{N}$ & $\mathrm{M}$ & $\mathrm{SD}$ & $\mathrm{t}$ & $\mathrm{p}$ \\
\hline Private & 80 & 73.4 & 10 & & \\
\hline & & & & -1.2 & 0.2 \\
\hline Public & 49 & 75.5 & 9 & & \\
\hline
\end{tabular}

Table 4: Differences of Job Sector on the scale of employee resilience scale among Employees ( $\mathrm{N}=129)$

Note: $\mathrm{N}=129,{ }^{*} p<0.01$
In table 4 as the p value is greater than 0.05 and nonsignificant, it's indicate that there is no significant difference in the level of employee resilience among public and private sector employees.

\section{Discussion}

The organizational support and employee resilience are two important variables that effect 'employee's life. The research was undertaken to investigate the role of perceived organizational support on employee resilience among employees. The purpose of this study was to investigate the effect of organizational support on employee resilience that how well the organization support their employees in their wellbeing, growth, and how much the organization consider and value the goals of their employees and to highlight the different qualities of the employees on work setting that how well they perform their tasks during work either they easily do the tasks or feel difficulties during work.

The first hypothesis pertaining to the correlation of organizational support and employee resilience is supported by the findings. So, there is a positive correlation between perceived organizational support and employee resilience. Research proved that if one variable perceived organizational support increases the other variable employee resilience also increases, if one variable decreases the other variable also decreases. This is an exploratory finding that's why no previous literature to support this findings.

The second hypothesis related to the impact of perceived organizational support on employee resilience is supported by the findings. As perceived organizational support is directly proportional to employee resilience so it has an impact on employee resilience. This hypothesis proved to be true because perceived organizational support proves to be an important factor for employees to show resilience, without organizational support the employees working in any organization are not resilient in their work. This is an exploratory finding that's why no previous literature to support this findings.

The third hypothesis pertaining that organizational support and employee resilience will vary in terms of public and private employees. The results depicted in this study support that the level of perceived organizational support is higher in Public employees as compared to private employees and there is no significant difference between private and public employees on employee resilience. This hypothesis proves true because the Public 


\section{Mental Health \& Human Resilience International Journal}

organizations give more support to their employees in terms of incentives, encouragement, admiration, respect and care. While private organizations show less support than Public organizations, and there is no significant difference between Public and private sector employees on employee resilience. This is an exploratory finding that's why no previous literature to support this findings.

\section{Conclusion}

The current research entitled "organizational support as increment in employee resilience: a comparative study among public and private employees". The results showed that there is significant positive correlation between organizational support and employee resilience. The results depicted in this study support that the level of organizational support is higher in Public organizations as compared to private and there is no significant difference between public and private sector employees on employee resilience.

\section{References}

1. Eisenberger R, Fasolo PM, Davis-LaMastro V (1990) Effects of perceived organizational support on employee diligence, innovation, and commitment. Journal of Applied Psychology 75(1): 51-59.

2. Eisenberger R, Huntington R,Hutchison S, Sowa D (1986) Perceived organizational support. Journal of Applied Psychology 71(3): 500-507.
3. Baird R, Heugten K, Walker B, Nilakant V (2013) Adaptive Resilience - How Organisations Responded in Christchurch. University of Canterbury and Christchurch, New Zealand.

4. Avey JB, Luthans F, Jensen SM (2009) Psychological capital: A positive resource for combating employee stress and turnover. Human Resource Management 48(5): 677-693.

5. Allen D, Shore L, Griffeth R (1999) A model of perceived organizational support. Unpublished manuscript, University of Memphis and Georgia State University.

6. De Meuse KP, Marks ML, Dai G (2011) Organizational downsizing, mergers and acquisitions, and strategic alliances: Using theory and research to enhance practice. In: Zedeck S (Eds.), APA handbook of industrial and organizational psychology, pp: 729768.

7. Sadaf, Rabia, Shama, Sumbal (2010) Perceived organizational support as predictor of organizational commitment. Perceived Organizational Support as Predictor of Organizational Commitment. 